\title{
UV Deprivation Influences Social UV Preference in Juvenile Sticklebacks
}

\author{
Ricarda Modarressie $^{1}$, Christian Günther ${ }^{1}$, and Theo C. M. Bakker ${ }^{*}$ \\ ${ }^{1}$ University of Bonn \\ *Corresponding author (Email: tbakker@evolution.uni-bonn.de)
}

Citation - Modarressie, R., Günther, C., \& Bakker, T. C. M. (2015). UV deprivation influences social UV preference in juvenile sticklebacks. Animal Behavior and Cognition, 2(2), 186-199. doi: 10.12966/abc.05.05.2015

\begin{abstract}
Social aggregations occur in many different animal taxa and mainly result from non-random assortment. Investigating factors that shape and maintain the composition of social aggregations are among others a main topic for understanding ecological speciation processes. Aggregation decisions are mediated by olfactory and visual cues, which in many animals are extended into the UV part of the electromagnetic spectrum. Here, we were interested in developmental plasticity of social preferences with respect to UV radiation in aquatic organisms. Specifically, we tested whether different lighting environments with respect to UV wavelengths during early life stages influence the shoaling preference in juvenile threespine sticklebacks (Gasterosteus aculeatus). Family (full-sibling) groups were split and reared under UV-lacking (UV-) and UV-present (UV+) lighting conditions. Subsequent shoal choice experiments, in which test fish from both rearing conditions could simultaneously choose between a shoal seen behind a UV-blocking (UV-) and a shoal seen behind a UV-transmitting (UV+) filter, revealed a significant effect of lighting condition during rearing on association preference. Test fish that had been deprived of UV spent significantly more time near the UV- shoal compared to the test fish reared under full-spectrum lighting conditions. The results are discussed with respect to plasticity of the visual system and environmental lighting conditions.
\end{abstract}

Keywords - Ultraviolet radiation and vision; Shoaling; Threespine stickleback; Habitat lighting condition, Gasterosteus aculeatus; Developmental plasticity; Ecological speciation

Social aggregations are a widespread phenomenon and occur in many different animal taxa (for review see Krause \& Ruxton, 2002). Aggregating with others provides benefits for a single individual but also bears costs e.g., in terms of enhanced competition for food (Krause, 1994) or the risk of getting infected with parasites (Poulin, 1999). Single individuals gain benefits by joining a group of conspecifics, e.g., due to a reduced predation risk (Foster \& Treherne, 1981; Landeau \& Terborgh, 1986; Magurran, 1990), enhanced vigilance (Kenward, 1987) and increased foraging success (Pitcher, Magurran, \& Winfield, 1982; Street \& Hart, 1985). It is assumed that in general the benefits are greater than the costs, so that social aggregations are adaptive (Krause \& Ruxton, 2002). Most social aggregation systems arise by non-random assortment, in which the grouping decision of an individual is influenced by different factors such as group size (Griffiths \& Magurran, 1997), familiarity (Barber \& Ruxton, 2000; Frommen \& Bakker, 2004; Frommen, Mehlis, Brendler, \& Bakker, 2007; Hesse, Bakker, Baldauf, \& Thünken, 2012) or conspecificity (Ward, Axford, \& Krause, 2002). As a result of non-random assortment within species evolutionary divergence and ecological speciation may arise (Bolnick et al., 2003; Hochberg, Sinervo, \& Brown, 2003). Ecological speciation is defined as the process by which barriers to gene flow (reproductive isolation) evolve between populations as a result of ecologically-based divergent selection (Rundle \& Nosil, 2005; Schluter, 2000). The first component that is required for ecological speciation is an ecological source of divergent selection (Rundle \& Nosil, 2005; Schluter, 2000). Therefore, 
investigating ecological factors that shape and maintain the composition of social aggregations are among others a main topic for understanding ecological speciation processes.

In many different animal taxa, the visual sensitivity is extended into the ultraviolet (UV) part of the spectrum (Jacobs, 1992; Losey et al., 1999; Silberglied, 1979; Tovée, 1995). UV signals play a significant role in diverse terrestrial and aquatic taxa during social interactions such as mate choice (e.g., Andersson \& Amundsen, 1997; Bennett, Cuthill, Partridge, \& Maier, 1996; Cummings, Rosenthal, \& Ryan, 2003; Kemp, 2007; Lim, Li, \& Li, 2008; Rick \& Bakker, 2008a; Rick, Modarressie, \& Bakker, 2006; Robertson \& Monteiro, 2005; Secondi, Lepetz, \& Théry, 2012) and aggressive behavior (e.g., Alonso-Alvarez, Doutrelant, \& Sorci, 2004; Bajer, Molnár, Török, \& Herczeg, 2011; Rémy, Grégoire, Perret, \& Doutrelant, 2010; Rick \& Bakker, 2008b; Siebeck, 2004; Whiting et al., 2006). In sticklebacks, which aggregate to more or less large and dense groups called shoals ranging from a few to up to several hundreds of individuals (Ranta \& Kaitala, 1991), shoal choice is also influenced by UV light in that individual fish prefer to associate with UV-reflecting shoal mates significantly longer than with nonreflecting ones (Modarressie, Rick, \& Bakker, 2006).

Shoaling fishes are good model systems to study visual factors that influence grouping decisions. Shoaling behavior is a well-studied phenomenon and, although in nature mixed species shoals do also exist (Ward et al., 2002), the composition of fish shoals is usually very homogeneous regarding the appearance of individuals (Ward \& Krause, 2001). For example, experimental studies showed preferences of individual fish for shoal mates with similar body coloration (black and white mollies: McRobert \& Bradner, 1998; zebrafish: Rosenthal \& Ryan, 2005; Saverino \& Gerlai, 2008).

Non-random assortment of shoals may be based on visual cues, and directed by early social experience (Krause \& Ruxton, 2002). Engeszer, Ryan, and Parichy (2004) demonstrated association preferences of cross-reared zebrafish (Danio rerio) from two alternative color morphs for the shoal with which the individual was raised with, irrespective of its own color. Similar results were obtained by Hesse et al. (2012) on a cichlid fish. The influence of early learning on sexual preferences are well-known in various taxa (mammals: Kendrick, Hinton, Atkins, Haupt, \& Skinner, 1998; birds: Bateson, 1978; ten Cate \& Vos, 1999; fishes: Verzijden \& ten Cate, 2007; for a review see Verzijden et al., 2012).

In communication systems where visual signals play a major role, communication is strongly dependent on the interaction between the signal and the receiver's sensory system (Endler \& Basolo, 1998). This interaction is influenced on three levels by the lighting environment (Fuller, Noa, \& Strellner, 2010): immediate direct effects on the efficacy of social signals, developmental plasticity of the visual system and social signals, and genetic adaptation of the visual system and social signals. In threespine sticklebacks (Gasterosteus aculeatus) populations for example, a shift in the perceptual sensitivity of females as well as in the nuptial coloration of males occurred with a red shift in the light environment (Boughman, 2001; McDonald \& Hawryshyn, 1995). However, it is often unclear which of the three above-mentioned mechanisms are involved (but see Fuller \& Noa, 2010; Fuller et al., 2010).

Threespine sticklebacks, a small shoal-forming fish, inhabit a wide range of different habitats on the northern hemisphere including coastal marine waters, brackish waters, clear lakes or streams and teastained freshwaters (Bell \& Foster, 1994; Wootton, 1976, 1984). Habitats can differ remarkably in their lighting properties either naturally e.g., due to elevated humic acid concentrations, (e.g., peat lochs in Scotland; MacColl, El Nagar, \& de Roij, 2013) or due to ongoing human induced pollution (like in the Baltic Sea; Bonsdorff, Blomqvist, Mattila, \& Norkko, 1997). Transmission spectra of water bodies are affected by their turbidity. In naturally turbid waters, short wavelengths including ultraviolet light (UV: 280-400nm) will be filtered or scattered first from the electromagnetic spectrum. Sticklebacks will thus be a good model system to investigate whether habitat-lighting properties, especially the absence or presence of UV wavelengths, during early life stages influence association preferences.

In the present study, we were especially interested in the developmental plasticity of social UV preferences as preferences may be shaped by the lighting environment during ontogeny and early social experience. In fishes, plasticity of the visual system including UV contingent upon lighting environment is well-known from studies in which fish had been raised under different lighting conditions (e.g., Fuller, Carleton, Fadool, Spady, \& Travis, 2005; Fuller \& Noa, 2010; Fuller et al., 2010; Shand et al., 2008). 
There also occur more pre-programmed changes in the visual system of fishes. In salmonid fishes, for instance, UV sensitivity diminishes during smoltification and reappears during the late juvenile or adult stage, which is based on a hormonally induced change in UV cone density and in the expression of opsins (e.g., Bowmaker \& Kunz, 1987; Cheng \& Novales Flamarique, 2007; Novales Flamarique, 2000, 2005; Raine, Coffin, \& Hawryshyn, 2010). A similar ontogenetic change has been observed in breams (Shand et al., 2008), and in the Australian lungfish (Neoceratodus forsteri) where the UV cones disappear in the adult stage, and the ocular media become non-transmitting for UV wavelengths (Hart, Bailes, Vorobyev, Marshall, \& Collin, 2008).

To study developmental plasticity of UV preferences, we split stickleback full-sibling groups after fertilisation and assigned them to two different lighting conditions: one sibling group was reared under full-spectrum (UV+: 300-800 nm) and the other under UV-absent lighting condition (UV-: 400-800 $\mathrm{nm})$. Subsequent shoal choice experiments were conducted to evaluate the importance of habitat lighting (UV+ or UV-) condition on the development of social preferences.

\section{Method}

\section{Experimental Subjects and Rearing Conditions}

Juvenile sticklebacks (Figure 1) were laboratory-bred offspring from a stationary population caught at the start of the breeding season in 2005 from a shallow pond near Bonn, Euskirchen, Germany $\left(50^{\circ} 38^{\prime} \mathrm{N} / 6^{\circ} 47^{\prime} \mathrm{E}\right)$. The pond has clear water and an expanded, light-flooded, shallow shore zone with sparse vegetation. Previous studies have shown a role of UV signals in social communications (e.g., Rick et al., 2006; Rick \& Bakker, 2008a, b, c). After fertilisation, eggs were taken out of the nests and each single clutch was split into two halves, which were assigned to two different lighting conditions that differed in their spectral transmission of UV-A wavelengths (UV-B radiation was lacking in both treatments) and in overall brightness (light intensity profiles were similar to those in Figure 2a of Rick \& Bakker, 2010). One half of the clutch was assigned to full-spectrum (UV+) and the second half to UVlacking (UV-) rearing condition. Group size was standardized to 20 fish about three months after hatching. Lighting conditions were generated by two optical filters (UV+: GS-2485 and UV-: GS-233, Röhm Darmstadt, Germany; for transmission spectra see Figure 1 in Rick \& Bakker, 2010. The filters differed in quantal flux by $18 \%$ ), which were mounted on the top of the holding aquaria filled with tapwater. Illumination was provided by fluorescent tubes (True Light, Natural Daylight 5500, 36 Watt, 120 $\mathrm{cm}$ ) hanging $15 \mathrm{~cm}$ above the water surface. These lights contain a proportion of UV-A similar to natural skylight. The fish were kept at $17 \pm 2{ }^{\circ} \mathrm{C}$ under a $16: 8 \mathrm{~h}$ light:dark regime with a dimming phase (over the entire light spectrum) during the morning and the evening that lasted half an hour. Fish were fed with defrosted Artemia ad libitum. We established 16 full-sibling groups from 16 different parental pairs. Fish that were inactive during the whole testing period (see below) were excluded from analyses. All fish were held under the two lighting conditions for at least 6 months after fertilization. 


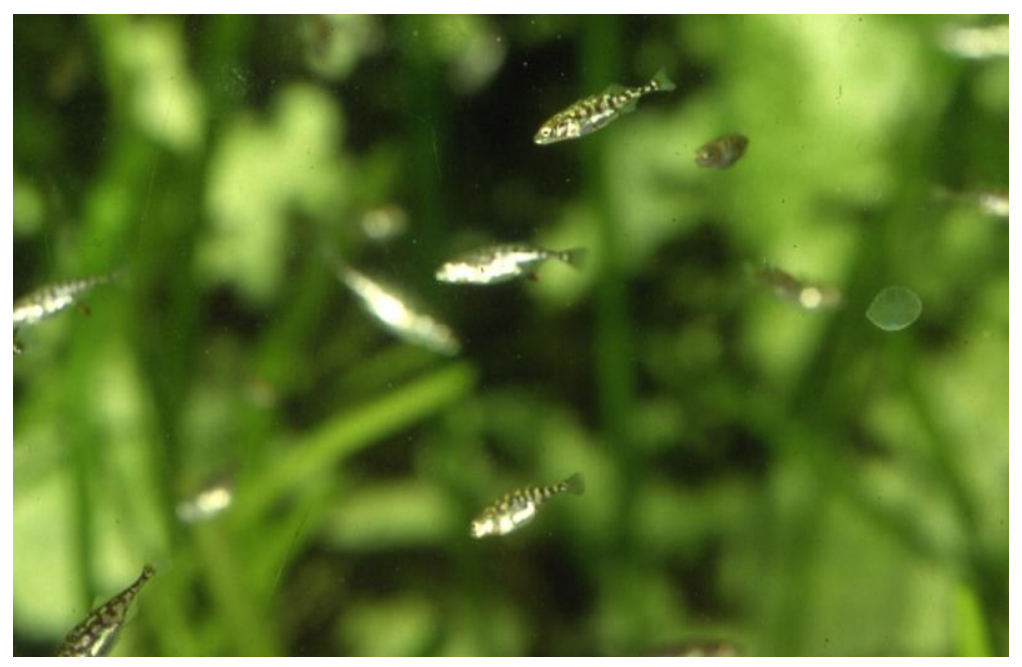

Figure 1. Shoaling juvenile threespine sticklebacks (photo by T. C. M. Bakker).

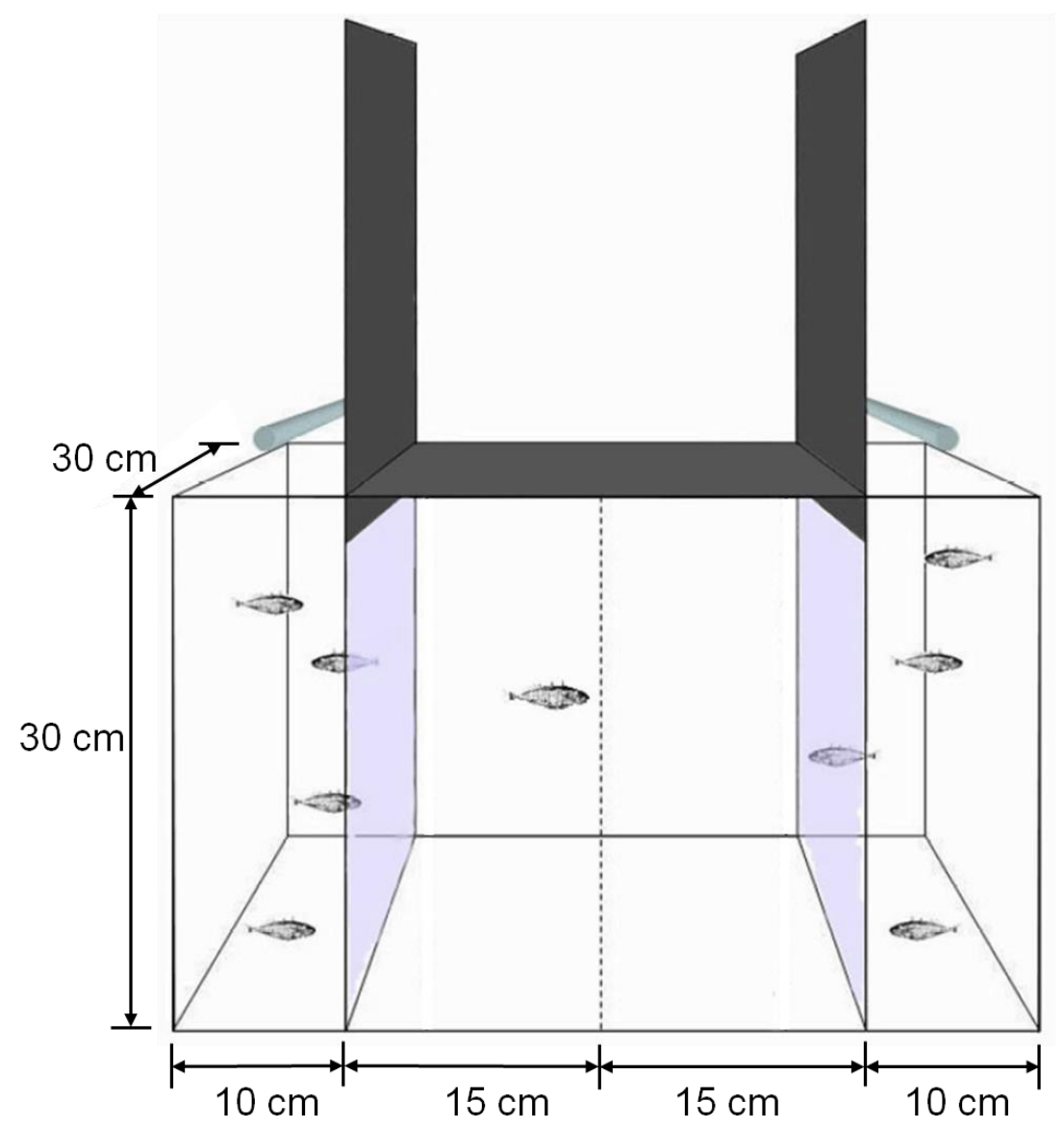

Figure 2. The test aquarium used to measure shoaling and habitat preferences. The aquarium was divided into three compartments by olfactory-proof fixed UV+ Plexiglas partitions. In the left and right shoal compartments, we placed two shoals of each four size-matched fish in the shoal choice tests and no fish in the habitat choice tests. The test fish, which was either raised under UV+ or UV- condition, was placed in the middle section. Between the compartments there were optical ultraviolet or neutral density filters (UV+, UV-, ND1 or ND2) and an opaque partition. Filters and the opaque partition could be lifted from a distance by a rope. In the Figure, the opaque partitions had been lifted. In front of the aquarium, a webcam recorded fish movements. The line drawn on the front and back pane visually divided the choice arena into two equal halves. Indicated are the fluorescent tubes installed above the shoal compartments. The choice arena was covered on top by an opaque gray sheet. 


\section{Experimental Set-up}

The test aquarium $(50 * 30 * 30 \mathrm{~cm}, 1 * \mathrm{w} * \mathrm{~h})$ was divided into three compartments by olfactoryproof fixed UV+ Plexiglas partitions that were transmitting wavelengths between 300-800 nm (GS-2485, Röhm Plexiglas, Germany) (Figure 2). The aquarium was filled with tap-water up to a depth of $26 \mathrm{~cm}$. To exclude confounding effects of previous trials, water was replenished after each trial. The two side walls and the back pane of the choice aquarium were fitted out with gray, opaque plastic sheets that reflected moderately in the UV-A (see Modarressie \& Bakker, 2007). The front pane remained clear for observations via a webcam. Each of the two outer sections $(10 * 30 * 30 \mathrm{~cm}, 1 * \mathrm{w} * \mathrm{~h})$ formed a shoal compartment and the middle one $(30 * 30 * 30 \mathrm{~cm}, 1 * \mathrm{w} * \mathrm{~h})$ the choice arena. The choice arena was divided into two equal halves by a black line that was drawn on both the front and back pane of the aquarium. In front of each shoal compartment there was an opaque partition that could be lifted from a distance by a rope. The two shoal compartments contained a shoal of four size-matched individuals each that were introduced shortly before the introduction of the test fish. After each trial, shoals were exchanged by another set of individuals. Illumination was given by two fluorescent tubes (True Light, Natural Daylight 5500, 36 Watt, $120 \mathrm{~cm}$ ) installed $2 \mathrm{~cm}$ above each shoal compartment (light intensity profiles were similar to those in Figure 2 b of Rick \& Bakker, 2010). A black curtain surrounded the setup, to prevent potentially confounding disturbances from outside.

The top of the choice arena was covered with an opaque gray plastic sheet. Therefore, incidence of light into test arena was nearly only given through the shoal compartments. Two optical filters (UV+ and UV-; equivalent to those used to generate light conditions during rearing) were inserted in front of both shoal compartments, which could be lifted from a distance by a rope. Therefore, one shoal was seen in full-spectrum light (UV+) and the other one in a spectrum lacking the UV-A spectral range (UV-). Test fish were gently taken from the holding tanks with a hand net and introduced, one at a time, in the middle part of the test aquarium. After 2 min of acclimatization the opaque partitions in front of the shoal compartments were lifted and the $20 \mathrm{~min}$ period of testing was started. This was followed by further 2 min of acclimatization in which the opaque partitions were put down again, and the two optical filters exchanged between sides. Thereafter, a second testing phase of $20 \mathrm{~min}$ using the same fish was started with reversed filter positions. Time test fish spent on either UV+ or UV- side was measured. Test fish were unfamiliar and unrelated to the fish of the stimulus shoals and only used in one trial (consisting of two testing phases).

Fish behavior was recorded by a webcam connected to a laptop. Shoaling preference was quantified from video recordings during $10 \mathrm{~min}$ per sub-trial and started once the test fish had seen both shoals, that is, had been in both halves of the choice arena. The association times based on the presence (of at least half the length of the fish) in one or the other half $(15 \mathrm{~cm}$ ) of the choice arena were used in the analyses as they correlated well with the association times based on the presence in a $5 \mathrm{~cm}$ association zone in front of each shoal (Spearman rank correlation coefficients for UV+ and UV- siblings associated with both UV+ or UV- shoals varied between 0.741 and 0.906 , all $p<0.001$ ).

The two optical filters (UV+, UV-) differed in wavelengths transmission and thus showed also a difference in brightness. To test whether fish preferred different brightness conditions independently of wavelength composition, the same experiments were conducted as mentioned above, but with two neutral density filters (ND1 - Lee 209, Zilz, Germany, and ND2 - Cotech 298, Zilz, Germany). The neutral density filters were transmitting wavelengths between $300 \mathrm{~nm}$ and $800 \mathrm{~nm}$ and only alter the amount of transmitted light without changing spectral composition (for transmission spectra see Figure 1 in Rick \& Bakker, 2010). Therefore, fish seen through the ND1 filter appear brighter compared to fish seen through the ND2 filter (light intensity profiles were similar to those in Figure 2c of Rick \& Bakker, 2010).

Furthermore, we tested whether fish had a habitat preference by conducting the same experiments (UV and ND) but with no stimulus shoals in the two outer compartments. To test for family effects four fish from each family, two full-siblings reared under UV+ and two siblings under UV- lighting conditions, were used in the UV shoal choice experiments. In the ND shoal choice and habitat choice control experiments, only two fish from each family were used, one had been reared under UV+ and one 
under UV- lighting condition. In the habitat choice control experiments, UV and ND filters were changed between the two testing phases of $20 \mathrm{~min}$. The order of filter use was alternated between subsequent tests. The order of UV shoal choice, ND shoal choice, and habitat choice experiments varied between families. Five fish of one family and rearing condition were randomly selected from their full-sibling group before the start of the set of experiments, transferred to a separate tank, maintained under the same conditions as before, and served as test fish. Shoals were composed of four size-matched full-siblings from the UV+ families, and were unrelated to the test fish.

All fish were measured as to standard length and body mass. The individual condition factor (CF) was calculated after: $\mathrm{CF}=100 * M / S L^{3}$ \{with $M=$ body mass $(\mathrm{g}), S L=$ standard length $(\mathrm{cm})$; Bolger \& Connolly, 1989\}. Films were analyzed blind meaning that the observer was naïve with respect to filter type as well as filter position.

Visual models, in which color variables are calculated as viewed by conspecifics by taking into account the visual sensitivities of sticklebacks and the ambient light (e.g., Rick \& Bakker, 2008c), were not considered for the present study. It is likely that rearing conditions influenced light sensitivity physiologically and/or morphologically (Chapman, Morrell, Tosh, \& Krause , 2010; Fuller et al., 2005, 2010; Fuller \& Noa, 2010; Kroger, Bowmaker, \& Wagner, 1999; Kroger, Braun, \& Wagner, 2001; Kroger, Campbell, \& Fernald, 2001; Novales Flamarique, Cheng, Bergstrom, \& Reimchen, 2013; Shand et al., 2008). Thus, fish reared in UV+ / UV- light environments are likely to have slightly different spectral sensitivities. Therefore, because of the lack of knowledge of the exact spectral sensitivities, visual modeling is not possible.

\section{Statistical Analysis}

Association preferences were expressed as \% time spent in the concerning half of the choice arena relative to the total test time $(10 \mathrm{~min})$. We used the $\mathrm{R} 2.4 .1$ statistical package (R Development Core Team, 2006) for analyses. Linear mixed-effects models (LME) were fitted to the data by using the lme function in the nlme library. Proportional data were arcsin square-root transformed in order to make the data normally distributed. The \% time near the UV-lacking shoal was used as dependent variable in the LME. Rearing condition, CF, $S L, M$, order of test fish (first or second test fish per family), and the interactions of rearing condition with the other variables were included as explanatory variables. Family was entered as random factor and never removed from the models to control for family-specific preferences. Non-significant explanatory variables were stepwise removed from the model in the order of statistical relevance. The models were compared with likelihood-ratio tests (LRT) that follow a $\chi^{2}$ distribution. Hence, degrees of freedom always differed by one. Given $p$-values are two-tailed throughout. Single comparisons were made with $t$ tests.

\section{Ethical note}

Animal care and experimental procedures were in accordance with the legal requirements of Germany. No additional license was required for this study.

\section{Results}

In the UV shoal choice experiment we separately tested four fish from 14 families each, two had been reared under UV+ and two under UV- lighting conditions. Association times of the two test fish from each rearing condition were averaged per family. Fish standard length was similar for the UV+ and UV- full-siblings (mean of family mean $\pm S D: 2.47 \mathrm{~cm} \pm 0.35$ and $2.52 \pm 0.14$, respectively, $p=0.18$ ). Lighting condition (UV+ and UV-) during rearing had a significant effect on test fish association preferences (Table 1, Figure 3A). When comparing family means of $\%$ association time between rearing conditions, fish reared under UV- lighting conditions preferred to associate with shoals lacking UV reflections (UV-) significantly longer than with UV+ shoals (paired $t$ test: $t=3.79, d f=13, p=0.002$; 
Figure 3A). UV+ reared fish showed no significant preference for either the shoal behind the UV- or UV+ optical filter (paired $t$ test: $t=1.27, d f=13, p=0.23$; Figure 3A). Relative association preference differed significantly between UV- and UV+ reared fish (paired $t$ test: $t=-3.343, d f=13, p=0.005$; Table 1 , Figure 3A). Further, the order (first or second test fish per family) as well as the standard length (SL) of fish tested from each family had significant effects on time fish spent in front of the UV- shoal (Table 1). No significant effect of family was detected (Table 1).
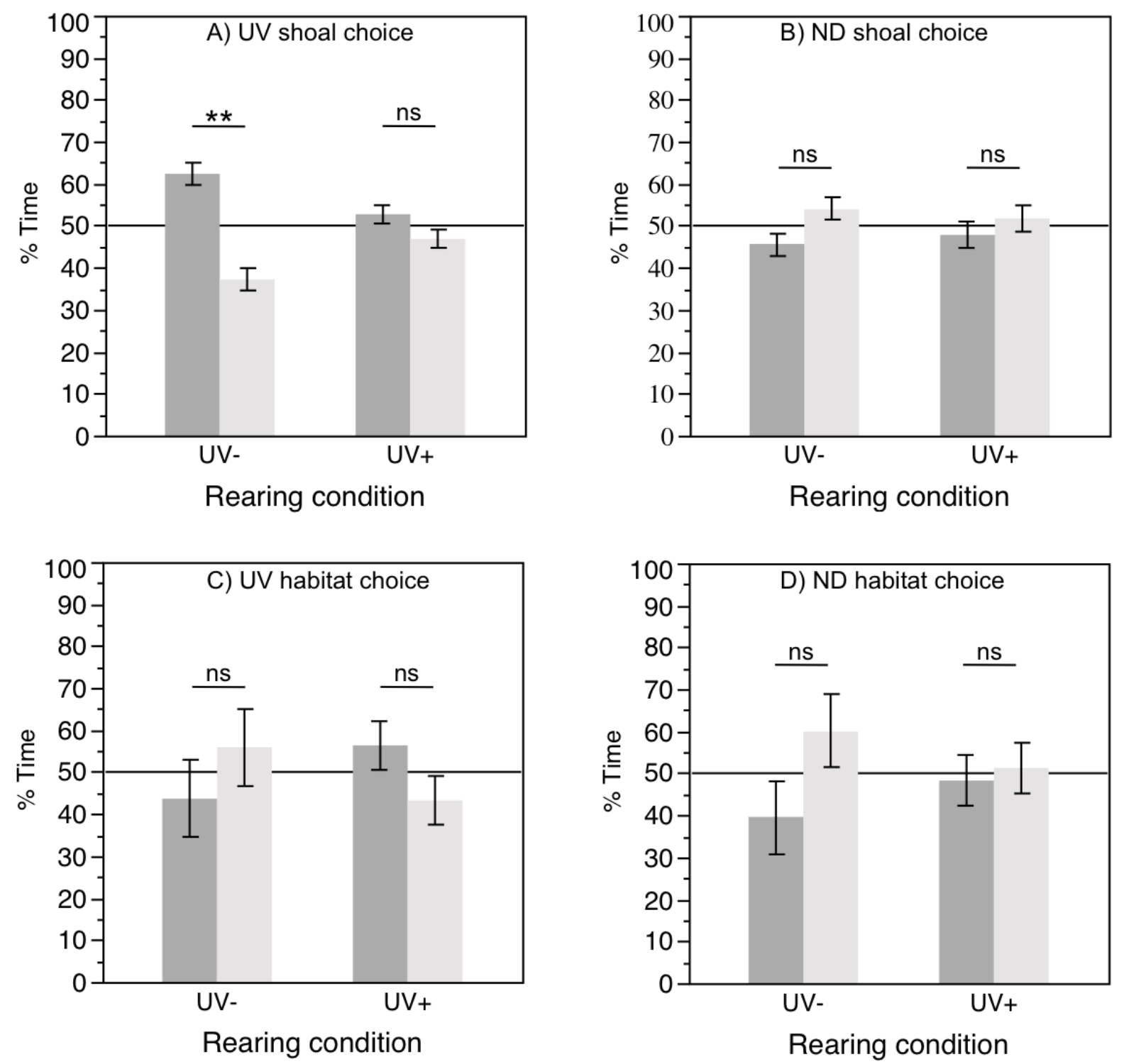

Figure 3. Mean $( \pm S E$ ) time in \% spent by test fish in front of A) shoals seen through the UV- (dark gray bars) or UV+ (light gray bars) optical filter. Rearing condition (UV-, UV+) significantly influenced shoaling preference; B) shoals seen through the ND2 (dark gray bars) or ND1 (light gray bars) optical filter. Test fish from the two different rearing conditions (UV+, UV-) showed no significant preference for either the ND2 or ND1 shoal; C) compartments (without a shoal) seen through the UV- (dark gray bars) or UV+ (light gray bars) optical filter. Test fish showed no significant UV habitat preference; D) compartments (without a shoal) seen through the ND2 (dark gray bars) or ND1 (light gray bars) optical filter. Test fish showed no significant ND habitat preference. ${ }^{* *} p<0.01, \mathrm{~ns}=$ not significant (paired $t$ tests on untransformed data). Lines at $50 \%$ indicate random choice. 
Table 1

UV Shoal Choice Experiments.

Analysis of variables affecting the proportion of time test fish reared either under UV+ or UV-lighting conditions spent near the shoal seen through the UV-blocking (UV-) filter

\begin{tabular}{|c|c|c|c|c|c|c|c|c|c|c|}
\hline & $\begin{array}{c}\text { Dependent } \\
\text { variable }\end{array}$ & $N$ & Explanatory variable & $\Delta d f$ & $\chi^{2}$ & $p$ & $\begin{array}{c}\text { Random } \\
\text { factor }\end{array}$ & $\Delta d f$ & $\chi^{2}$ & $p$ \\
\hline a) & $\begin{array}{l}\text { \% time near } \\
\text { UV-shoal }\end{array}$ & 28 & rearing condition & 1 & 7.25 & 0.007 & family & 1 & 1.17 & 0.28 \\
\hline \multirow[t]{9}{*}{ b) } & $\%$ time near & 28 & rearing condition & 1 & 10.62 & 0.001 & family & 1 & 1.17 & 0.28 \\
\hline & UV-shoal & 28 & order & 1 & 8.98 & 0.002 & & & & \\
\hline & & 28 & $S L$ & 1 & 5.76 & 0.017 & & & & \\
\hline & & 28 & $\mathrm{CF}$ & 1 & 1.99 & 0.16 & & & & \\
\hline & & 28 & $M$ & 1 & 0.002 & 0.97 & & & & \\
\hline & & 28 & rearing condition $*$ order & 1 & 0.18 & 0.68 & & & & \\
\hline & & 28 & rearing condition $* S L$ & 1 & 0.77 & 0.38 & & & & \\
\hline & & 28 & rearing condition $* \mathrm{CF}$ & 1 & 2.62 & 0.11 & & & & \\
\hline & & 28 & rearing condition $* M$ & 1 & 1.91 & 0.17 & & & & \\
\hline
\end{tabular}

Note. The most parsimony linear mixed-effect model a) (\% time $\sim$ rearing condition, random $=$ family) revealed a significant effect of rearing condition but no effect of family on association preference. Including condition factor (CF), standard length $(S L)$, body mass $(M)$, and order of test fish (first or second test fish per family) as explanatory variables as well as the interactions of these with rearing condition to the model b) resulted in significant effects of rearing condition, order and $S L$ on association time. Non-significant factors were stepwise excluded from the model.

In the control shoal choice tests for brightness differences, we used one fish from each of 16 families that were reared under UV+ and 14 fish of the same families, one per family, that were reared under UV- lighting condition. When comparing \% association time, both test fish reared under UV+ and under UV- lighting conditions showed no significant preference for either the shoal seen in a brighter (ND1) or darker (ND2) appearing environment (paired $t$ tests, all $p>0.14$; Table 2, Figure 3B). Body measures as well as family had no significant effects on the behavior of test fish (Table 2).

Table 2

ND Shoal Choice Experiments.

Analysis of variables affecting the proportion of time test fish reared either under UV+ or UV-lighting conditions spent near the shoal seen through the ND1 filter

\begin{tabular}{|c|c|c|c|c|c|c|c|c|c|c|}
\hline & $\begin{array}{c}\text { Dependent } \\
\text { variable }\end{array}$ & $N$ & Explanatory variable & $\Delta d f$ & $\chi^{2}$ & $p$ & $\begin{array}{c}\text { Random } \\
\text { factor }\end{array}$ & $\Delta d f$ & $\chi^{2}$ & $p$ \\
\hline a) & $\begin{array}{l}\text { \% time near } \\
\text { ND1 shoal }\end{array}$ & 30 & rearing condition & 1 & $<0.001$ & 0.99 & family & 1 & $<0.001$ & 0.99 \\
\hline b) & $\begin{array}{l}\% \text { time near } \\
\text { ND1 shoal }\end{array}$ & $\begin{array}{l}30 \\
30 \\
30 \\
30 \\
30 \\
30 \\
30 \\
\end{array}$ & $\begin{array}{l}\text { rearing condition } \\
S L \\
\mathrm{CF} \\
M \\
\text { rearing condition } * S L \\
\text { rearing condition } * \mathrm{CF} \\
\text { rearing condition } * M\end{array}$ & $\begin{array}{l}1 \\
1 \\
1 \\
1 \\
1 \\
1 \\
1\end{array}$ & $\begin{array}{l}0.37 \\
1.33 \\
0.32 \\
0.97 \\
0.52 \\
1.02 \\
0.75 \\
\end{array}$ & $\begin{array}{l}0.54 \\
0.25 \\
0.57 \\
0.33 \\
0.47 \\
0.31 \\
0.39 \\
\end{array}$ & family & 1 & 1.17 & 0.28 \\
\hline
\end{tabular}

Note. The most parsimony linear mixed-effect model a) (\% time $\sim$ rearing condition, random $=$ family) revealed no significant effect of rearing condition and family on association time. Including condition factor (CF), standard length (SL), and body mass $(M)$ of test fish as explanatory variables as well as the interaction of these with rearing condition to the model b) resulted in no significant effects of all variables on association time.

In the control tests for habitat differences, test fish from both rearing treatments (one per rearing treatment of each 13 families) showed no significant preference for a habitat either in the UV+/UV- or ND1/ND2 habitat control experiment (paired $t$ tests, all $p>0.27$; Figures 3C \& 3D). Simultaneously presented shoals did not significantly differ in mean $S L$ or mean body mass (all $p>0.20$ ) in all shoal 
choice treatments. In the UV shoal choice experiments with UV- reared test fish, shoals in the left or right shoal compartment tended to differ in condition factor, i.e., shoals presented on the right side tended to have a higher condition factor (paired $t$ test: $t=-1.894, d f=31, p=0.07$ ). However, we found no preference of test fish for either the shoal with higher or lower CF in this treatment (paired $t$ test: $t=$ $0.393, d f=15, p=0.70)$.

\section{Discussion}

The results of our study suggest that lighting conditions (UV+, UV-) during early life-stages significantly influence later association preference in threespine sticklebacks for UV-lacking (UV-) or UV-reflecting (UV+) shoal mates. Association preference for UV- shoals differed significantly between fish deprived of UV during rearing and fish reared under full-spectrum conditions including UV wavelengths. Sticklebacks inhabit a wide range of different habitats ranging from clear to tannin-stained waters that differ remarkably in spectral composition, and therefore populations are exposed to different levels of UV radiation during development. Population substructure could arise and potentially be maintained by diversifying environmental lighting conditions, which may be one ecological cause of divergent selection, the first component of ecological speciation (Rundle \& Nosil, 2005; Schluter, 2000). Populations from such heterogeneous habitats e.g., due to more or less dense vegetation or variation in turbidity would form good study systems for ecological speciation (e.g., Maan \& Seehausen, 2011).

Fish of the two treatments will have experienced a different appearance of their full-siblings during rearing. Thus the different social UV preferences of full-siblings when reared under different UV lighting conditions may be experientially based. In various animal taxa, early experience has been shown to influence subsequent social preferences at least in cross-species experiments (e.g., fishes: Engeszer et al., 2004; Hesse et al., 2012; McCann \& Carlson, 1982; Spence \& Smith, 2007; Warburton \& Lees, 1996; birds: Blaustein, 1983; Bolhuis, 1991). If intraspecific association patterns would be consistent over the life cycle of an individual, that is, are also reflected in mate preferences, this may lead to behavioral isolation, which can be strengthened through reinforcement (Kozak et al., 2015). Potentially, these processes could lead to ecological speciation (Maan \& Seehausen, 2011).

Another reason for the change in social UV preference contingent upon lighting condition during rearing may be plasticity of the visual sensory system. Visual systems of fishes including the UV component are highly plastic. Plasticity, i.e., individual phenotypic change related to environmental change, has been observed in opsin expression (Fuller et al., 2005, 2010; Hofmann, O'Quin, Smith, \& Carleton, 2010; Shand et al., 2008; but see Novales Flamarique et al., 2013), the frequencies of spectral cone types (Kroger et al., 1999; Novales Flamarique et al., 2013), transmission of ocular media (Kroger, Cambell et al., 2001b), and neural sensitivity such as spectral sensitivities of cone horizontal cells in the retina (Kroger, Braun et al., 2001). In view of the limited plasticity of the relative number of cones and opsin expression in sticklebacks, Novales Flamarique et al. (2013) question whether visual plasticity in sticklebacks and other fishes will be ecologically meaningful. In addition, fish brains are highly plastic (e.g., nine-spined sticklebacks Gonda, Herczeg, \& Merilä, 2009; Gonda, Välimäki, Herczeg, \& Merilä, 2012) and add another level of plasticity of vision (for review see Ruthazer \& Aizenman, 2010).

UV- reared test fish significantly preferred shoal mates lacking UV reflections, whereas UV+ reared testfish showed no preference for either UV-lacking or UV-reflective shoals. The latter result is at odds with that of a former study, in which test fish significantly preferred to join UV-reflective shoals over non-reflecting ones (Modarressie et al., 2006). Fish from Modarressie et al. (2006) stemmed from a natural population and were only housed for three months in the laboratory. But fish also had different preferences for brightness of shoals in the two studies suggesting that further test conditions may have been different like difference in light intensity during rearing and the age at which fish were tested (see Buske \& Gerlai, 2011 for age effects of shoaling in zebrafish). Fish used in Modarressie et al. (2006) were adults caught shortly before the breeding season, and thus were probably half a year older than the fish used in the present study. Nevertheless, the UV-lacking and UV-present lighting conditions during rearing resulted in significant differences in shoaling preferences between both groups. 
The habitat control experiments (for the ND and UV environments) suggest that differences in preferences in the main experiment were based on shoaling preferences rather than habitat preferences (see also Rick \& Bakker, 2008a, c; Rick, Bloemker, \& Bakker, 2012). In the brightness control experiments, fish from both rearing conditions showed no significant preference for either the brighter (ND1) or darker (ND2) appearing shoal (see also Modarressie, Rick, \& Bakker, 2013; Modarressie et al., 2006; Rick \& Bakker, 2008a, b; Rick et al., 2006). This strengthens the result of the main experiment, and suggests that shoaling preferences are based on hue differences rather than brightness differences. The results also suggest that the difference in overall brightness during rearing caused by the two filters had no decisive influence on shoal choice behavior.

In fishes, there are various studies that show genetic effects of the lighting environment on visual systems including UV sensitivity (e.g., Boughman, 2001; Endler, Basolo, Glowacki, \& Zerr, 2001; Endler, Westcott, Madden, \& Robson, 2005; Fuller et al., 2010; Jokela-Määttä, Smura, Aaltonen, AlaLaurila, \& Donner, 2007; McDonald \& Hawryshyn, 1995; Novales Flamarique et al., 2013). Compared to crosses of diversifying populations or artificial selection lines, the power of our analysis using one population and only two test fish per family was too low to detect family effects.

Testing order (first or second test fish per family) as well as standard length of test fish had a significant effect on association preference. Only standard length of fish tested secondly of a particular family and only from the UV+ rearing regime correlated negatively with association time in front of the UV-lacking shoal (UV+ first fish, $p=0.55$ and second fish, $p=0.02$; UV- first fish $p=0.47$ and second fish $p=0.27$ ), which caused the overall significant effect. We have no plausible explanation for this result, but it is conceivable that the secondly tested fish had experienced more stress, which may have had a somewhat diverting effect on its behavior. However, if this is true we would have expected a similar pattern in secondly tested fish from the UV- rearing regime, which was not observed.

Summarizing, depriving sticklebacks the first half year of their lives of UV radiation changed their UV association preference compared to their full-siblings that were reared under full-spectrum illumination. Regardless of the underlying mechanism of this plasticity in UV shoaling preference (changed appearance of tank mates, plasticity of visual and/or neural systems), diversifying lighting conditions may trigger sub-structuring of populations. This may be an initial step towards ecological speciation. The threespine stickleback is an ideal species to study divergent selection as stickleback speciation seems to be primarily the result of ecological processes and speciation in sticklebacks is often rapid (Boughman, 2007). Since the integration of molecular genetics in evolutionary research on stickleback (Peichel et al., 2001), the threespine stickleback has developped as a supermodel species for evolutionary biology (Gibson, 2005; Barber \& Nettleship, 2010) facilitating the study of the genetic basis of speciation. Concerning UV preferences, further research is needed to assess whether consistent microhabitat heterogeneity can be found in nature that would lead to divergent selection on visual preferences and preferred visual signals, which often coevolve (e.g., Bakker, 1993; Rick, Mehlis, \& Bakker, 2011), and whether visual preferences in the juvenile stage persist in the reproductive stage.

\section{Acknowledgements}

We thank Timo Thünken, Joachim G. Frommen and Ingolf P. Rick for discussion, Leif Engqvist for statistical advice, and anonymous reviewers for constructive comments. The study was supported by the Deutsche Forschungsgemeinschaft (BA 2885/1-3). We gratefully acknowledge the permission of Jürgen Wittler and Thomas Schaper for catching sticklebacks at the field site.

\section{References}

Alonso-Alvarez, C., Doutrelant, C., \& Sorci, G. (2004). Ultraviolet reflectance affects male-male interactions in the blue tit (Parus caeruleus ultramarinus). Behavioral Ecology, 15, 805-809.

Andersson, S., \& Amundsen, T. (1997). Ultraviolet colour vision and ornamentation in bluethroats. Proceedings of the Royal Society of London Series B, 264, 1587-1591. 
Bajer, K., Molnár, O. R., Török, J., \& Herczeg, G. (2011). Ultraviolet nuptial colour determines fight success in male European green lizards (Lacerta viridis). Biology Letters, 7, 866-868.

Bakker, T. C. M. (1993). Positive genetic correlation between female preference and preferred male ornament in sticklebacks. Nature, 363, 255-257.

Barber, I., \& Nettleship, S. (2010). From 'trash fish' to supermodel: The rise and rise of the threespined stickleback in evolution and ecology. Biologist, 57, 15-21.

Barber, I., \& Ruxton, G. D. (2000). The importance of stable schooling: Do familiar sticklebacks stick together? Proceedings of the Royal Society of London Series B, 267, 151-155.

Bateson, P. (1978). Sexual imprinting and optimal outbreeding. Nature, 273, 659-660.

Bell, M. A., \& Foster, S. A. (1994). Introduction to the evolutionary biology of the threespine stickleback. In M. A. Bell \& S. A. Foster (Eds.), The evolutionary biology of the threespine stickleback (pp. 1-27). Oxford: Oxford University Press.

Bennett, A. T. D., Cuthill, I. C., Partridge, J. C., \& Maier, E. J. (1996). Ultraviolet vision and mate choice in zebra finches. Nature, 380, 433-435.

Blaustein, A. R. (1983). Kin recognition mechanisms: Phenotypic matching or recognition alleles. The American Naturalist, $121,749-754$.

Bolger, T., \& Connolly, P. L. (1989). The selection of suitable indices for the measurement and analysis of fish condition. Journal of Fish Biology, 34, 171-182.

Bolhuis, J. J. (1991). Mechanisms of avian imprinting: A review. Biological Review, 66, 303-345.

Bolnick, D. I., Svanback, R., Fordyce, J. A., Yang, L. H., Davis, J. M., Hulsey, C. D., \& Forister, M. L. (2003). The ecology of individuals: Incidence and implications of individual specialization. The American Naturalist, 161, 1-28.

Bonsdorff, E., Blomqvist, E. M., Mattila, J., \& Norkko, A. (1997). Coastal eutrophication: Causes, consequences and perspectives in the Archipelago areas of the northern Baltic Sea. Estuarine Coastal and Shelf Science, $44,63-72$.

Boughman, J. W. (2001). Divergent sexual selection enhances reproductive isolation in sticklebacks. Nature, 411, 944-948.

Boughman, J. W. (2007). Speciation in sticklebacks. In S. Östlund-Nilsson, I. Mayer, \& F. A. Huntingford, (Eds), Biology of the three-spined stickleback (pp. 83-126). Boca Raton, FL: CRC Press.

Bowmaker, J. K., \& Kunz, Y. W. (1987). Ultraviolet receptors, tetrachromatic colour vision and retinal mosaics in the brown trout (Salmo trutta): Age-dependent changes. Vision Research, 27, 2101-2108.

Buske, C., \& Gerlai, R. (2011). Shoaling develops with age in zebrafish (Danio rerio). Progress in NeuroPsychopharmacology \& Biological Psychiatry, 35, 1409-1415.

Chapman, B. B., Morrell, L. J., Tosh, C. R., \& Krause, J. (2010). Behavioural consequences of sensory plasticity in guppies. Proceedings of the Royal Society of London Series B, 277, 1395-1401.

Cheng, C. L., \& Novales Flamarique, I. (2007). Chromatic organization of cone photoreceptors in the retina of rainbow trout: Single cones irreversibly switch from UV (SWS1) to blue (SWS2) light sensitive opsin during natural development. The Journal of Experimental Biology, 210, 4123-4135.

Cummings, M. E., Rosenthal, G. G., \& Ryan, M. J. (2003). A private ultraviolet channel in visual communication. Proceedings of the Royal Society of London Series B, 270, 897-904.

Endler, J. A., \& Basolo, A. L. (1998). Sensory ecology, receiver biases and sexual selection. Trends in Ecology and Evolution, 13, 415-420.

Endler, J. A., Basolo, A., Glowacki, S., \& Zerr, J. (2001). Variation in response to artificial selection for light sensitivity in guppies (Poecilia reticulata). The American Naturalist, 158, 36-48.

Endler, J. A., Westcott, D. A., Madden, J. R., \& Robson, T. (2005). Animal visual systems and the evolution of color patterns: sensory processing illuminates signal evolution. Evolution, 59, 1795-1818.

Engeszer, R. E., Ryan, M. J., \& Parichy, D. M. (2004). Learned social preference in zebrafish. Current Biology, 14, 881-884.

Foster, S. A., \& Treherne, J. E. (1981). Evidence for the dilution effect in the selfish herd from fish predation on a marine insect. Nature, 293, 466-467.

Frommen, J. G., \& Bakker, T. C. M. (2004). Adult three-spined sticklebacks prefer to shoal with familiar kin. Behaviour, 141, 1401-1409.

Frommen, J. G., Mehlis, M., Brendler, C., \& Bakker, T. C. M. (2007). Shoaling decisions in three-spined sticklebacks (Gasterosteus aculeatus) - familiarity, kinship and inbreeding. Behavioral Ecology and Sociobiology, 61, 533-539.

Fuller, R. C., Carleton, K. L., Fadool, J. M., Spady, T. C., \& Travis, J. (2005). Genetic and environmental variation 
in the visual properties of the bluefin killifish Luciana goodei. Journal of Evolutionary Biology, 18, 516523.

Fuller, R. C., \& Noa, L. A. (2010). Female mating preferences, lighting environment, and a test of sensory bias in bluefin killifish. Animal Behaviour, 80, 23-35.

Fuller, R. C., Noa, L. A., \& Strellner, R. S. (2010). Teasing apart the many effects of lighting environment on opsin expression and foraging preference in bluefin killifish. The American Naturalist, 176, 1-13.

Gibson, G. (2005). The synthesis and evolution of a supermodel. Science, 307, 1890-1891.

Gonda, A., Herczeg, G., \& Merilä, J. (2009). Habitat-dependent and -independent plastic responses to social environment in the nine-spined stickleback (Pungitius pungitius) brain. Proceedings of the Royal Society of London Series B, 276, 2085-2092.

Gonda, A., Välimäki, K., Herczeg, G., \& Merilä, J. (2012). Brain development and predation: Plastic responses depend on evolutionary history. Biology Letters, 8, 249-252.

Griffiths, S. W., \& Magurran, A. E. (1997). Schooling preferences for familiar fish vary with group size in a wild guppy population. Proceedings of the Royal Society of London Series B, 264, 547-551.

Hart, N. S., Bailes, H. J., Vorobyev, M., Marshall, N. J., \& Collin, S. P. (2008). Visual ecology of the Australian lungfish (Neoceratodus forsteri). BMC Ecology, 8, 21.

Hesse, S., Bakker, T. C. M., Baldauf, S. A., \& Thünken, T. (2012). Kin recognition by phenotype matching is family- rather than self-referential in juvenile cichlid fish. Animal Behaviour, 84, 451-457.

Hochberg, M. E., Sinervo, B., \& Brown, S. P. (2003). Socially mediated speciation. Evolution, 57, 154-158.

Hofmann, C. M., O'Quin, K. E., Smith, A. R., \& Carleton, K. L. (2010). Plasticity of opsin gene expression in cichlids from Lake Malawi. Molecular Ecology, 19, 2064-2074.

Jacobs, G. H. (1992). Ultraviolet vision in vertebrates. American Zoologist, 32, 544-554.

Jokela-Määttä M., Smura, T., Aaltonen, A., Ala-Laurila, P., \& Donner, K. (2007). Visual pigments of Baltic Sea fishes of marine and limnic origin. Visual Neuroscience, 24, 389-398.

Kemp, D. J. (2007). Female butterflies prefer males bearing bright iridescent ornamentation. Proceedings of the Royal Society of London Series B, 274, 1043-1047.

Kendrick, K. M., Hinton, M. R., Atkins, K., Haupt, M. A., \& Skinner, J. D. (1998). Mothers determine sexual preferences. Nature, 395, 229-230.

Kenward, R. E. (1987). Hawks and doves: Attack success and selection in goshawk flights at wood pigeons. Journal of Animal Ecology, 47, 449-460.

Kozak, G. M., Roland, G., Rankhorn, C., Falater, A., Berdan, E. L., \& Fuller, R. C. (2015). Behavioral isolation due to cascade reinforcement in Lucania killifish. The American Naturalist, 185, 491-506.

Krause, J. (1994). The influence of food competition and predation risk on size-assortative shoaling in juvenile chub (Leuciscus cephalus). Ethology, 96, 105-116.

Krause, J., \& Ruxton, G. D. (2002). Living in groups: Oxford series in ecology and evolution. Oxford: Oxford University Press.

Kroger, R. H. H., Bowmaker, J. K., \& Wagner, H. J. (1999). Morphological changes in the retina of Aequidens pulcher (Cichlidae) after rearing in monochromatic light. Vision Research, 39, 2441-2448.

Kroger, R. H. H., Braun, S. C., \& Wagner, H. J. (2001). Rearing in different photic and chromatic environments modifies spectral responses of cone horizontal cells in adult fish retina. Visual Neuroscience, 18, 857-864.

Kroger, R. H. H., Campbell, M. C. W., \& Fernald, R. D. (2001). The development of the crystalline lens is sensitive to visual input in the African cichlid fish, Haplochromis burtoni. Vision Research, 41, 549-559.

Landeau, L., \& Terborgh, J. (1986). Oddity and the 'confusion effect' in predation. Animal Behaviour, 34, 13721380.

Lim, M. L. M., Li, J., \& Li, D. (2008). Effect of UV-reflecting markings on female mate-choice decisions in Cosmophasis umbratica, a jumping spider from Singapore. Behavioral Ecology, 19, 61-66.

Losey, G. S., Cronin, T. W., Goldsmith, T. H., Hyde, D., Marshall, N. J., \& McFarland, W. N. (1999). The UV visual world of fishes: A review. Journal of Fish Biology, 54, 921-943.

Maan, M. E., \& Seehausen, O. (2011). Ecology, sexual selection and speciation. Ecology Letters, 14, 591-602.

MacColl, A. D. C., El Nagar, A., \& de Roij, J. (2013). The evolutionary ecology of dwarfism in three-spined sticklebacks. Journal of Animal Ecology, 82, 642-652.

Magurran, A. E. (1990). The adaptive significance of schooling as an anti-predator defence in fish. Annales Zoologici Fennici, 27, 51-66.

McCann, L. I., \& Carlson, C. C. (1982). Effects of cross-rearing on species identification in zebrafish and pearl danios. Developmental Psychology, 15, 71-74.

McDonald, C. G., \& Hawryshyn, C. W. (1995). Intraspecific variation of spectral sensitivity in threespine 
stickleback (Gasterosteus aculeatus) from different photic regimes. Journal of Comparative Physiology A, $176,255-260$.

McRobert, S. P., \& Bradner, J. (1998). The influence of body coloration on shoaling preferences in fish. Animal Behaviour, 56, 611-615.

Modarressie, R., \& Bakker, T. C. M. (2007). A limited role for ultraviolet radiation when threespine sticklebacks Gasterosteus aculeatus prey upon Daphnia. Canadian Journal of Fisheries and Aquatic Sciences, 64, $1573-1580$.

Modarressie, R., Rick, I. P., \& Bakker, T. C. M. (2006). UV matters in shoaling decisions. Proceedings of the Royal Society of London Series B, 273, 849-397 854.

Modarressie, R., Rick, I. P., \& Bakker, T. C. M. (2013). Ultraviolet reflection enhances the risk of predation in a vertebrate. Current Zoology, 59, 151-159.

Novales Flamarique, I. (2000). The ontogeny of ultraviolet sensitivity, cone disappearance and regeneration in the sockeye salmon (Oncorhynchus nerka). Journal of Experimental Biology, 203, 1161-1172.

Novales Flamarique, I. (2005). Temporal shifts in visual pigment absorbance in the retina of Pacific salmon. Journal of Comparative Physiology A, 191, 37-49.

Novales Flamarique, I., Cheng, C. L., Bergstrom, C., \& Reimchen, T. E. (2013). Pronounced heritable variation and limited phenotypic plasticity in visual pigments and opsin expression of threespine stickleback photoreceptors. The Journal of Experimental Biology, 216, 656-667.

Peichel, C. L., Nereng, K., Ohgi, K. A., Cole, B. L. E., Colosimo, P. F., Buerkle, C. A., \& Kingsley, D. M. (2001). The genetic architecture of divergence between threespine stickleback species. Nature, 414, 901-905.

Pitcher, T. J., Magurran, A. E., \& Winfield, I. (1982). Fish in larger shoals find food faster. Behavioral Ecology and Sociobiology, 10, 932-934.

Poulin, R. (1999). Parasitism and shoal size in juvenile sticklebacks: conflicting selection pressures from different ectoparasites? Ethology, 105, 959-968.

R Development Core Team (2006). R: A Language and Environment for statistical Computing. R Foundation for Statistical Computing, Vienna, Austria. http://www.R-project.org.

Raine, J. C., Coffin, A. B., \& Hawryshyn, C. W. (2010). Systemic thyroid hormone is necessary and sufficient to induce ultraviolet-sensitive cone loss in the juvenile rainbow trout retina. The Journal of Experimental Biology, 213, 493-501.

Ranta, E., \& Kaital, V. (1991). School size affects individual feeding success in three-spined sticklebacks (Gasterosteus aculeatus L.). Journal of Fish Biology, 39, 733-737.

Rémy, A., Grégoire, A., Perret, P., \& Doutrelant, C. (2010). Mediating male-male interactions: The role of the UVblue crest coloration in blue tits. Behavioral Ecology and Sociobiology, 64, 1839-1847.

Rick, I. P., \& Bakker, T. C. M. (2008a). UV wavelengths make female three-spined sticklebacks (Gasterosteus aculeatus) more attractive for males. Behavioral Ecology and Sociobiology, 62, 439-445.

Rick, I. P., \& Bakker, T. C. M. (2008b). Males do not see only red: UV wavelengths and male territorial aggression in the three-spined stickleback. Naturwissenschaften, 95, 631-638.

Rick, I. P., \& Bakker, T. C. M. (2008c). Color signalling in conspicuous red sticklebacks: Do ultraviolet signals surpass others? BMC Evolutionary Biology, 8, 189.

Rick, I. P., \& Bakker, T. C. M. (2010). Ultraviolet light influences habitat preferences in a fish under predation risk. Evolutionary Ecology, 24, 25-37.

Rick, I. P., Bloemker, D., \& Bakker, T. C. M. (2012). Spectral composition and visual foraging in the threespine stickleback (Gasterosteidae: Gasterosteus aculeatus L.): Elucidating the role of ultraviolet wavelengths. Biological Journal of the Linnean Society, 105, 359-368.

Rick, I. P., Mehlis, M., \& Bakker, T. C. M. (2011). Male red ornamentation is associated with female red sensitivity in sticklebacks. PLoS ONE, 6, e25554.

Rick, I. P., Modarressie, R., \& Bakker, T. C. M. (2006). UV wavelengths affect female mate choice in three-spined sticklebacks. Animal Behaviour, 71, 307-313.

Robertson, K. A., \& Monteiro, A. (2005). Female Bicyclus anynana butterflies choose males on the basis of their dorsal UV-reflective eyespot pupils. Proceedings of the Royal Society of London Series B, 272, 1541-1546.

Rosenthal, G. G., \& Ryan, M. J. (2005). Assortative preferences for stripes in danios. Animal Behaviour, 70, 10631066.

Rundle, H., \& Nosil, P. (2005). Ecological speciation. Ecology Letters, 8, 336-352.

Ruthazer, E. S., \& Aizenman, C. D. (2010). Learning to see: Patterned visual activity and the development of visual function. Trends in Neurosciences, 33, 183-192.

Saverino, C., \& Gerlai, R. (2008). The social zebrafish: Behavioral responses to conspecific, heterospecific, and 
computer animated fish. Behavioural Brain Research, 191, 77-87.

Schluter, D. (2000). The ecology of adaptive radiation. Oxford: Oxford University Press.

Secondi, J., Lepetz, V., \& Théry, M. (2012). Male attractiveness is influenced by UV wavelengths in a newt species but not in its close relative. PLoS ONE, 7, e30391.

Shand, J., Davies, W. L., Thomas, N., Balmer, L., Cowing, J. A., Pointer, M., \& Hunt, D. M. (2008). The influence of ontogeny and light environment on the expression of visual pigment opsins in the retina of the black bream, Acanthopagrus butcheri. The Journal of Experimental Biology, 211, 1495-1503.

Siebeck, U. E. (2004). Communication in coral reef fish: The role of ultraviolet colour patterns in damselfish territorial behaviour. Animal Behaviour, 68, 273-282.

Silberglied, R. E. (1979). Communication in the ultraviolet. Annual Review of Ecology and Systematics, 10, 373398.

Spence, R., \& Smith, C. (2007). The role of early learning in determining shoaling preferences based on visual cues in the zebrafish, Danio rerio. Ethology, 113, 62-67.

Street, N. G., \& Hart, P. J. B. (1985). Group size and patch location by the stoneloach, Noemacheilus barbatulus, a non-visually foraging predator. Journal of Fish Biology, 217, 785-792.

ten Cate, C., \& Vos, D. R. (1999). Sexual imprinting and evolutionary processes in birds: A reassessment. Advances in the Study of Behavior, 28, 1-31.

Tovée, M. J. (1995). Ultraviolet photoreceptors in the animal kingdom - their distribution and function. Trends in Ecology and Evolution, 10, 455-460.

Verzijden, M. N., \& ten Cate, C. (2007). Early learning influences species assortative mating preferences in Lake Victoria cichlid fish. Biology Letters, 3, 134-136.

Verzijden, M. N., ten Cate, C., Servedio, M. R., Kozak, G. M., Boughman, J. W., \& Svensson, E. I. (2012). The impact of learning on sexual selection and speciation. Trends in Ecology and Evolution, 27, 511-519.

Warburton, K., \& Lees, N. (1996). Species discrimination in guppies: Learned responses to visual cues. Animal Behaviour, 52, 371-378.

Ward, A. J. W., Axford, S., \& Krause, J. (2002). Mixed-species shoaling in fish: The sensory mechanisms and costs of shoal choice. Behavioral Ecology and Sociobiology, 52, 182-187.

Ward, A. J. W., \& Krause, J. (2001). Body length assortative shoaling in the European minnow, Phoxinus phoxinus. Animal Behaviour, 62, 617-621.

Whiting, M. J., Stuart-Fox, D. M., O'Connor, D., Firth, D., Bennett, N. C., \& Blomberg, S. P. (2006). Ultraviolet signals ultra-aggression in a lizard. Animal Behaviour, 72, 353-363.

Wootton, R. J. (1976). The biology of the sticklebacks. London: Academic Press.

Wootton, R. J. (1984). A functional biology of sticklebacks. London: Croom Helm. 